\title{
Out of Hours
}

\section{Television}

\section{THE GP WILL SEE YOU NOW GPs: Behind Closed Doors}

Tuesdays on Channel 5 at $9 \mathrm{pm}$ 29 April- 20 May 2014

The first of this fly-on-the-wall series set in a south-east London health centre was shown in the last week of April, at a time when the Chair and Secretary of the RCGP were making headlines about the importance of providing more resources for general practice so that GPs can provide a decent service. Dame Sally Davies, the Chief Medical Officer, had been uttering apocalyptic warnings about the over-prescription of antibiotics, and the 'antidepressants do more harm than good' debate had somehow reignited itself. With astonishing prescience almost all of these controversies were dealt with in the very first episode of the series.

It can't have been easy for the doctors, surgery staff, and patients to make this programme. There were clearly some questions about identity and confidentiality, because a few of the patients' faces were fuzzed-out. Two or three of them are clearly very aware of the camera in the consulting room. Nevertheless, the programme, which was extremely well-filmed, with witty cuts-outs and juxtapositions, succeeded in being entertaining and informing, without being patronising or cheesy, and managed to sustain a sense of lighthearted, slightly resigned, humanity and empathy throughout.

The notion that general practice just deals with coughs and colds was robustly dispelled. We saw a consultation to discuss a colectomy for severe inflammatory bowel disease, a horrific septic foot, which was subsequently amputated, a man with haematuria, a good demonstration of psychiatric, physical, and social comorbidity involving depression, diabetes, chronic pain, and hypertension, and a nicely-conducted consultation with a young epileptic woman who had been contemplating suicide. There were some cleverly interwoven pearls of wisdom from the senior GP featured in the film, including apposite comments about generic GP issues such as knowing your patient, continuity of care, and breaking bad news. When a patient suggested going to casualty because of breast pain she very persuasively, replied 'Casualty! Have you any idea how long the doctors there have been qualified?'. One of the excellent trainees gave a delightfully self-deprecating disquisition on the hidden agenda, in which he completely misinterpreted a young girl's interest in leaflets about contraception: she just wanted something to get under a radiator to retrieve a 50p piece. The practice showed a commendably unified approach to not prescribing antibiotics for respiratory

GPs: Behind Closed Doors. Image Courtesy of Channel 5 and Knickerbockerglory Ltd.

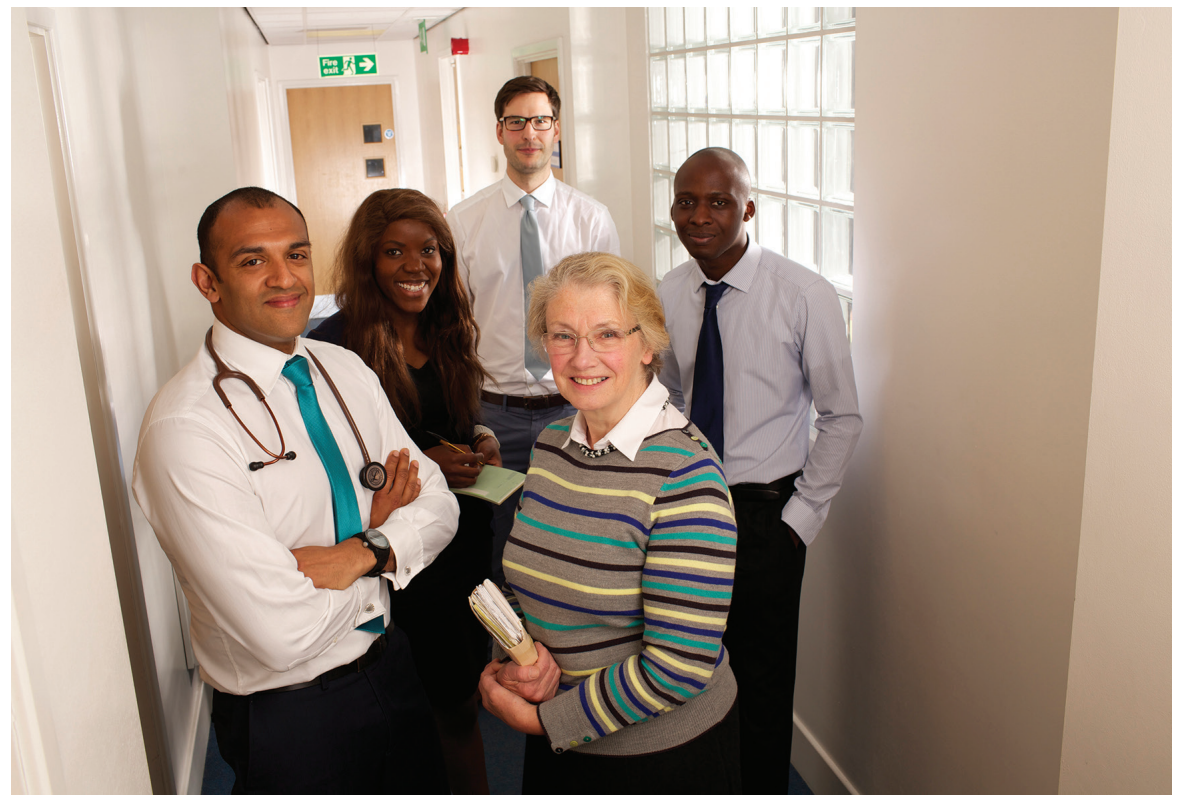

tract infections, except for a particularly nasty case of tonsillitis, in which the same trainee demonstrated, rather impressively I thought, that if the young smoker quit there and then he would save $£ 26830$ before he was 30 years old. There was a similar, measured approach to the use of antidepressants. Breast self-examination, the non-drug management of insomnia, and the importance of providing good access for young people were other highly salient topics that were touched on. In the first episode, at least, the front desk and back office scenes were less compelling; perhaps problems of confidentiality are more tricky in these settings.

Even more interesting, at least from my point of view, is what the GPs and staff thought of the film when they watched it themselves. There was no doubt that in a number of the consultations the presence of the computer was an unhelpful distraction, rather than something that contributed to communication. The consulting room geometry sometimes didn't look quite right. During one sensitive consultation the clattering of keyboard keys became almost deafening. Will this extended video feedback on an entire practice stimulate personal or organisational changes and, 'seeing us as others see us', will other GPs and surgery staff who watched this recognise their own practice foibles?

The programme ended with a few neat summaries of the health outcomes of some of the patients who were featured. It will be interesting to see how the series develops: will viewers be following the fortunes of their favourite GP or receptionist, or will continuity of care allow us to follow the ups and downs of patients with longerterm problems over time? Whatever, this unsanitised and warm-hearted account of inner-city primary care is a credit to the practice who bravely agreed to take part and a clear statement about the very important work they do.

\section{Roger Jones,}

BJGP Editor, London

E-mail: rjonesđarcgp.org.uk

DOI: 10.3399/bjgp14X680593 